Article

\title{
Impacts of COVID-19 on Diverse Farm Systems in Tanzania and South Africa
}

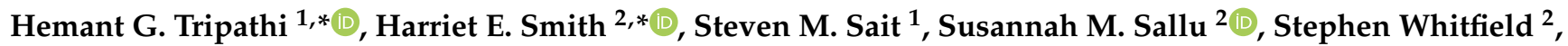 \\ Astrid Jankielsohn ${ }^{3}{ }^{D}$, William E. Kunin ${ }^{1}$, Ndumiso Mazibuko ${ }^{4}$ and Bonani Nyhodo ${ }^{4}$ \\ 1 Faculty of Biological Sciences, University of Leeds, Leeds LS2 9JT, UK; S.M.Sait@leeds.ac.uk (S.M.S.); \\ w.e.kunin@leeds.ac.uk (W.E.K.) \\ 2 School of Earth and Environment, University of Leeds, Leeds LS2 9JT, UK; s.sallu@leeds.ac.uk (S.M.S.); \\ S.Whitfield@leeds.ac.uk (S.W.) \\ 3 Small Grain Institute, Agriculture Research Council, Bethlehem 9702, South Africa; Jankielsohna@arc.agric.za \\ 4 National Agricultural Marketing Council, Arcadia, Pretoria 0002, South Africa; ndumiso@namc.co.za (N.M.); \\ bonani@namc.co.za (B.N.) \\ * Correspondence: hgtripathi05@gmail.com (H.G.T.); h.x.smith@leeds.ac.uk (H.E.S.)
}

check for updates

Citation: Tripathi, H.G.; Smith, H.E.; Sait, S.M.; Sallu, S.M.; Whitfield, S.; Jankielsohn, A.; Kunin, W.E.;

Mazibuko, N.; Nyhodo, B. Impacts of COVID-19 on Diverse Farm Systems in Tanzania and South Africa. Sustainability 2021, 13, 9863. https:// doi.org/10.3390/su13179863

Academic Editors: Aitazaz A. Farooque and Farhat Abbas

Received: 28 July 2021

Accepted: 27 August 2021

Published: 2 September 2021

Publisher's Note: MDPI stays neutral with regard to jurisdictional claims in published maps and institutional affiliations.

Copyright: (c) 2021 by the authors. Licensee MDPI, Basel, Switzerland This article is an open access article distributed under the terms and conditions of the Creative Commons Attribution (CC BY) license (https:// creativecommons.org/licenses/by/ $4.0 /)$.

\begin{abstract}
Emerging information on the interactions between the COVID-19 pandemic and global food systems have highlighted how the pandemic is accentuating food crises across Africa. Less clear, however, are how the impacts differ between farming systems. Drawing on 50 key informant interviews with farmers, village leaders and extension officers in South Africa and Tanzania, we identify the effects of COVID-19 and associated measures to curb the spread of the disease on farming production systems, the coping mechanisms adopted by farmers, and explore their longer-term plans for adaptation. We focus on a diverse range of production systems, from small-scale mixed farming systems in Tanzania to large-scale corporate farms in South Africa. Our findings highlight how COVID-19 restrictions have interrupted the supply chains of agricultural inputs and commodities, increasing the storage time for produce, decreasing income and purchasing power, and reducing labour availability. Farmers' responses were heterogeneous, with highly diverse small-scale farming systems and those less engaged with international markets least affected by the associated COVID-19 measures. Large-scale farmers were most able to access capital to buffer short-term impacts, whereas smaller-scale farms shared labour, diversified to subsistence produce and sold assets. However, compounded shocks, such as recent extreme climate events, limited the available coping options, particularly for smaller-scale and emerging farmers. The study highlights the need to understand the characteristics of farm systems to better equip and support farmers, particularly in contexts of uncertainty. We propose that policy actions should focus on (i) providing temporary relief and social support and protection to financially vulnerable stakeholders, (ii) job assurance for farmworkers and engaging an alternative workforce in farming, (iii) investing in farming infrastructure, such as storage facilities, digital communication tools and extension services, and (iv) supporting diversified agroecological farming systems.
\end{abstract}

Keywords: COVID-19; Africa; food systems; agriculture

\section{Introduction}

The coronavirus disease (COVID-19) spread rapidly across the globe, leading to global health emergencies and measures to curb the spread of the disease, which caused sharp declines in business activities, loss of employment and income and inevitable economic crises [1]. COVID-19 restrictions on the international and domestic movement of people and economic activities have also had direct and far-reaching impacts on global food systems [2-4]. Loss of income and the associated decline of purchasing power reduced the ability of people to access food, resulting in the decline of dietary diversity and consumption of nutrient-rich foods, disrupting agricultural input markets and threatening 
food production [1]. COVID-19 could push millions of people to starvation and give rise to a global hunger pandemic [5] and potential social unrest. There are concerns that impacts of the COVID-19 pandemic may reverse the progress made in achieving the Sustainable Development Goals (SDGs), so a sustainable post-pandemic recovery is therefore key [6].

In many ways, populations and food systems across Africa are perhaps less vulnerable to COVID-19, compared to other regions in the world [5], given the persistence of subsistence food production and shorter food supply chains, lower rates of urbanisation and population densities in many areas, alongside a youthful population [7]. However, key vulnerabilities stem from high and chronic levels of poverty [8], a reliance on food importexport markets, the informal nature of local food supply chains and impracticalities with social distancing and lockdowns amongst labour-intensive farming systems and informal economies [1]. The majority of agricultural systems and farmers across SSA already operate under contexts of high vulnerability, uncertainty and variability. SSA is one of the most vulnerable regions to the impacts of global climate change and variability $[9,10]$. Uncontrollable and potentially devastating crop pest and disease outbreaks are not unusual [11], with their prevalence linked to climate change [12]. Recent food crises and associated civil unrest have also been precipitated by global economic shocks [13]. Health systems and livelihoods across SSA are already burdened by high rates of infectious diseases, such as HIV / AIDS, tuberculosis and malaria [14]. COVID-19 is, therefore, an additional system shock that populations across the region must continue to cope with and adapt to.

Farmers' ability to cope with and adapt to shocks is sensitive to the local context and dependent on their available capacities, resources, prior experiences and knowledge [15-17]. In the context of agricultural systems across SSA, the impacts of COVID-19 are likely to be varied and broad [18], owing to the heterogeneous nature and diversity of the sector and production systems across the continent [19]. Similarly, the capacity of farmers to respond to COVID-19 will also be highly contextual and dependent on, for example, climatic extremes, agroecological context, country-specific restrictions, farmers' socio-economic conditions, production model and supply chain integration and available formal and informal institutional support [20].

Emerging evidence has shown how COVID-19 is affecting agricultural activities by disrupting supply chains, labour mobility and availability and access to essential farm inputs, such as fertilisers and pesticides [18]. The timing of national lockdowns coincided with harvests and planting times in different countries [18], often delaying the time-critical activities and affecting the quantity and quality of produce. The impacts and long-term consequences are likely to vary across SSA [5], be complex, contextual and dynamicdetermined by farm systems' characteristics and geographies [21]. However, the empirical evidence of the impacts of COVID-19 on agricultural systems across SSA is lacking [18], as are the compounded impacts of, for example, COVID-19, climate variability and pest and disease outbreaks.

Understanding the implications of COVID-19 and associated restrictions is necessary in supporting a sustainable post-pandemic recovery for farmers and farm systems across the region [22]. Investigating how COVID-19 impacted local-scale food production and how farmers adapted can support better understanding of farmer resilience. In turn, this can help inform coherent responses for a sustainable post-COVID-19 recovery [23].

This paper draws on qualitative data from two case-study sites (Figure 1) in the East Usambara Mountains, Muheza District, Republic of Tanzania (henceforth Tanzania) and Thabo Mofutsanyane District, Free State, South Africa, which collectively represent diverse farming systems and varied Government responses to the global COVID-19 pandemic. In response to calls for more resilient farming and food systems [23-25], our study aims to explore the implications of COVID-19 and associated national restrictions on diverse farm systems, with the following objectives:

- Identify the impacts of COVID-19 and associated restrictions on farm systems and farmer livelihoods; 
- Examine farmers' responses to the associated impacts of COVID-19 to understand how they differed between farming systems and identify factors that affected their abilities to cope;

- Identify additional shocks that further exacerbated the impacts of COVID-19.

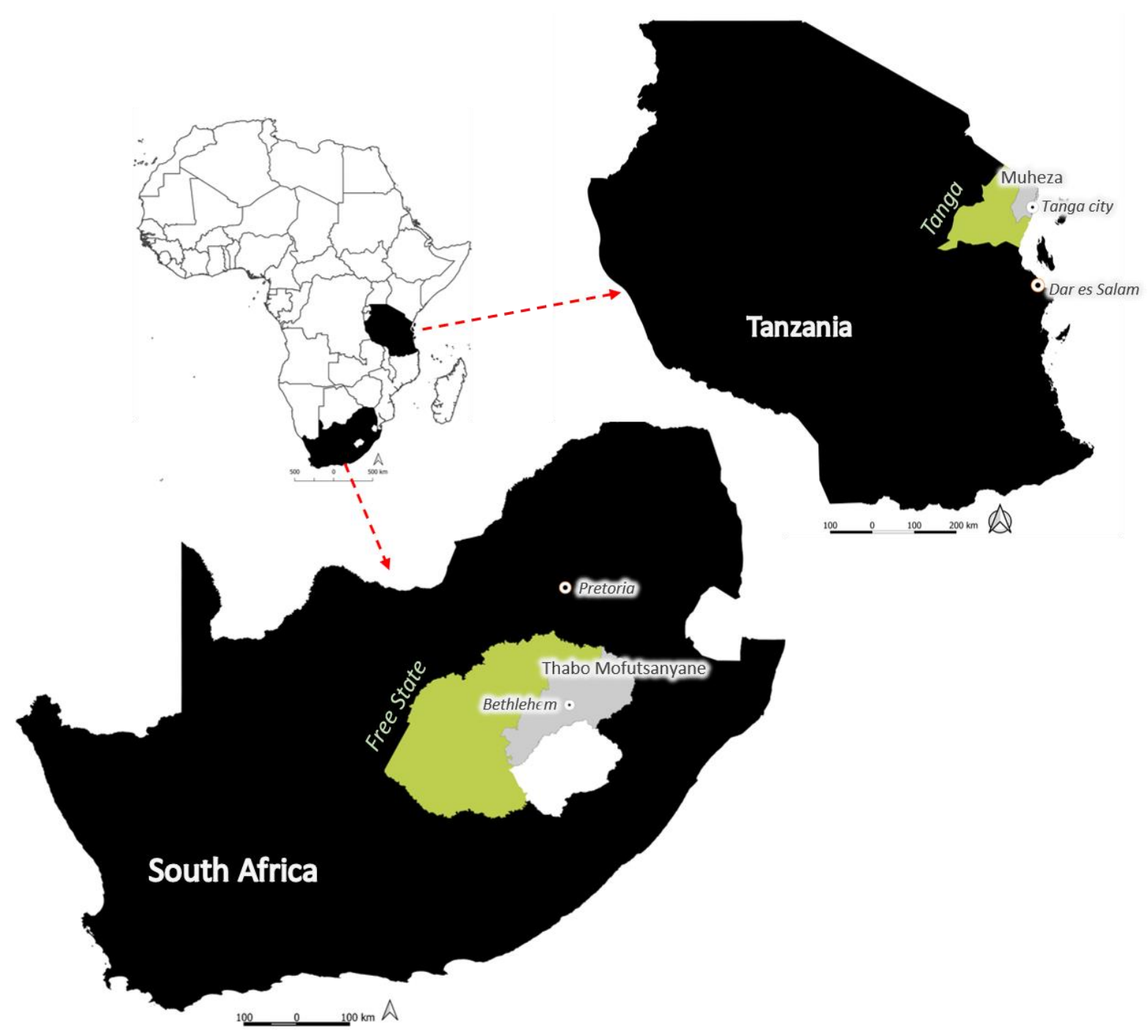

Figure 1. Map of case study sites: We conducted this study by interviewing farmers in Thabo Mofutsanyane district, Free State province in South Africa and Muheza district (East Usambara mountains) Tanga region of Tanzania. Bethlehem was the nearest town to the study sites in South Africa, and Tanga was the closest city to Tanzanian sites.

\section{Materials and Methods}

\subsection{Case Study Sites}

\subsubsection{Farming Systems}

In the East Usambara Mountains, Tanzania, commercial logging, an extensive tea plantation, the expansion of smallholder agriculture and forest conservation efforts have contributed to a landscape mosaic of forest and farms. Here, highland communities predominantly depend on highly diverse but low-input, mixed cropping, livestock (primarily zero-grazing dairy cattle and poultry) and agroforestry smallholder systems with farm sizes of 1-2 ha. Typical subsistence food crops include maize, beans, yams, banana and cassava; commercial crops include spices (cardamom, cinnamon, clove and black pepper), in addition to sugarcane, fruits and some horticultural produce (tomatoes, onions, green leaves). Even though past external interventions have promoted various soil and water 
management practices, farm management practices are largely traditional, including terraces, contouring, agroforestry and reduced tillage, alongside improved staple food crop varieties. Limited application of chemical inputs occurs in the area.

In Thabo Mofutsanyane District, South Africa, three scales of farming enterprises co-exist:

Small-scale farmers ( $<10 \mathrm{ha})$, primarily farming for local markets and subsistence and restricted to marginal lands in geographically remote areas or at higher altitudes. Some farmers have adopted particular conservation agriculture (CA) practices, such as intercropping, cover crops, mulching and zero or low tillage, to reduce crop stress from increasingly prevalent periodic drought conditions. Farm mechanisation for small-scale farms is limited.

Emergent farmers (50-200 ha), practising a mix of livestock (mainly cattle, sheep and pigs) and crop farming commercially, mainly for domestic markets and with mechanisation and equipment primarily supported through agriculture support programmes, e.g., AgriParks [26] or farmer cooperatives [27]. Typical crops grown include maize, potatoes and soybeans. These farmers received farming land through the Land Reform Redistribution Programme 1997 [28,29]. The emergent farmers have minimal take-up of CA practices.

Commercial farmers (>200 ha), who predominantly grow commodities such as maize, soy, wheat, apples and potatoes for domestic and export markets. They most often have the capital to invest in new innovations, information and technologies to increase yield, adaptability and profit, employ hired labour when required and evolve as per market demands [30]. Some of the commercial farmers have switched to conservation agriculture practices, such as cover cropping, minimum- and no-till, incorporation of livestock in crops and minimising agrochemicals to mitigate soil degradation and the impacts of drought.

\subsubsection{Agro-Climatic Conditions}

In the East Usambara mountains, there are typically two growing seasons: short rain (Vuli) from October to December, and long rain (Masika) from March to May, though occasionally a third (Mchoro) occurs from June-July, depending on location [31]. Annual rainfall is high at $1900 \mathrm{~mm}$ (ranging between 1200-2500 $\mathrm{mm}$ ), and temperature variation is moderate $\left(10-30^{\circ} \mathrm{C}\right)$ [31]. Diverse climatic differences across the region are dependent on elevation and aspect [32], with rainfall variability increasing [33]. In recent years, extreme climate events and increasing soil degradation rates have posed challenges for farmers in the area, particularly with timely crop planting and germination, crop pests and diseases, soil erosion and farm soil fertility $[34,35]$.

In Thabo Mofutsanyane District, the growing period coincides with the single annual rainy season during which most $(\sim 85 \%)$ of the annual rainfall (ranging between 530-650 $\mathrm{mm}$ ) occurs. Temperatures in the region range from $12-30{ }^{\circ} \mathrm{C}$ [36]. The region has extensive fertile and arable lands intermixed with pasture contributing significantly to its agricultural production. The farmers in the region have been facing longer dry spells and drought at the start of planting season and early onset (mid-March), and late cessation (mid-October) of frost for the last 4-5 years [37]. As a result, the growing season has been shorter than usual, with unpredictable planting times and standing crops becoming more vulnerable to winter stress, causing adverse agricultural production outcomes.

\subsubsection{National and Local COVID-19 Restrictions}

When the COVID-19 cases in Tanzania began to rise by the end of March 2020, the government imposed localised recommendations that restricted political meetings, public gatherings and community events, closing educational institutions and encouraging citizens to stay at home except for essential purposes. Some private organisations also imposed work from home directives. Following a further rise in COVID-19 cases in urban centres, on 14 April 2020, the Tanzanian government applied localised lockdowns in various towns nationwide [38]. Lockdowns in Tanzania were not policed intensively, and international travel bans were lifted shortly afterwards, on 18 May 2020. The neighbouring 
East African countries of Kenya and Uganda imposed more severe lockdowns from April to June 2021, including border closures and movement restrictions [39]. For example, reports indicated a $\sim 50 \%$ reduction of delivery trucks travelling across Tanzanian-Ugandan and Tanzanian-Kenyan borders [38]. This study focuses on the effect of lockdowns in the first half of 2020 as it aligns with the data collection period.

The South African government declared the COVID-19 pandemic a national disaster on 15 March 2020 and entered a 21-day lockdown on 27 March [40,41]. The lockdown prohibited all non-essential domestic and international travel and imposed a curfew on persons' movement and the opening of non-essential businesses and schools, with soldiers and police monitoring the streets. Grocery stores and wholesale produce markets, spaza shops (informal convenience shop business, usually run from home), and informal fruit and vegetable sellers required written permission from the local municipal authority to continue their businesses. Failure to abide by the curfew was punishable by a fine or a period of up to six months imprisonment. In the second lockdown from 20 April-1 May 2020, agriculture was recognised as an essential sector, and movement of relevant labour and goods was permitted with regulations on the number of employees inside the work premises or in the vehicles used by labourers. The Department of Agriculture, Land Reform and Rural Development (DALRRD) deployed intervention measures to reduce the negative impacts of COVID-19. DALRRD provided monetary assistance (USD 83 million) to smallscale farmers under the Proactive Land Acquisition Strategy (PLAS) programme and also through the Land Bank (USD 69,000). The South African Social Security Agency (SASSA) provided food parcels and vouchers to the vulnerable and food-insecure communities.

\subsection{Data Collection and Analysis}

We conducted a total of 50 key informant interviews (25 in each country (In South Africa we interviewed 8 emerging, 8 commercial and 9 small-scale farmers)) in the East Usambara mountains, Muheza District, Tanzania, and Thabo Mofutsanyane District in South Africa. Participants were purposively selected based on their local and regional context knowledge and farming experience; key informants comprised farmers, agricultural extension officers and traditional authorities. Data were collected May-June 2020 in Tanzania and September-October 2020 in South Africa.

Structured interviews were conducted in local languages by three enumerators ( 1 in Tanzania and 2 in South Africa). Given that interviews were conducted during the pandemic and during lockdown periods in both countries, interviews were conducted either in-person (taking place outside and following social distancing) or, where possible, remotely through phone calls. The interview comprised a set of open-ended questions and prompts to explore the impacts of COVID-19 on farming activities, pre-and post-harvesting practices, commodity markets, broader impacts on farming households and livelihoods and farmers' coping and adaptation mechanisms.

Interviews were audio-recorded and subsequently translated (from Sesotho and Afrikaans to English in South Africa, and Swahili to English in Tanzania) and transcribed by the same data collection team. Qualitative responses in the transcripts were explored and thematically analysed using Nvivo and Microsoft Excel software.

We conducted inductive thematic analysis, systematically identifying and matching recurring elements from the content of translated interview transcripts to create categories, which were subsequently collapsed to form themes [42-45]. Coding of qualitative data followed terms and narratives around the impacts of COVID-19 on farming activities and farmer livelihoods, and the subsequent coping mechanisms adopted by farmers. This helped us explore the range of impacts and farmer responses across the multiple production models that we investigated in this study. Data from both sites were compared to identify collective and unique narratives. 


\section{Results}

The impacts of COVID-19 and the responses of farmers varied depending on the type of production system. Across our study sites, small-scale producers operated in contexts of limited infrastructure-roads, irrigation, storage and markets, which isolated them geographically and economically. Such isolation limited their access to services and opportunities, affecting their ability to respond and recover from shocks. In contrast, the large-scale commercial farmers had access to capital and mechanisation and had the ability to anticipate shocks and procure inputs.

\subsection{Market Impacts}

Many smallholder farmers in Tanzania have strong international market connections, typically selling crops such as spices, yams, bananas and sugarcane to buyers from Kenya, India and nationally in Tanzania (principally from Dar es Salaam, Pemba and Zanzibar). With the closure of international borders between Tanzania and neighbouring countries and enforcement of domestic travel restrictions, market competition declined as buyers could not reach farms. Farmers were consequently faced with limited selling options, with some forced to sell spices locally at severely reduced amounts and prices. Cloves, for example, were previously selling at 15,000 Tz Shilling per $\mathrm{Kg}$, but at the time of data collection, prices had dropped by a reported $50 \%$. Concern and suspicion of travellers also affected farmers' willingness to receive potential buyers:

"When people came here from Dar es Salaam, people shouted things like 'that's Corona'. When there were buyers coming to my house, [ . . . ] I told them that it's better if possible to send them the crops. When they come here, other people will be afraid of them because people know that if you are coming from Dar es Salaam, there is a coronavirus, and you may infect others." (Farmer in Tanzania)

Markets for perishable products, such as bananas and yams, were significantly affected by the closure of the market in Tanga, the Region's capital Town and an important port market. This prevented the sale of products to consumers on Pemba and Zanzibar islands. Populations in Tanga Region, Zanzibar and Pemba are also majority Muslim. Travel restrictions coincided with Ramadan (23 April-23 May 2020), which is usually a peak selling period for yams. This led to a loss of sales and wasted produce. Sugarcane also suffered from reduced availability of domestic buyers. However, for some smallholders in Tanzania, who were more self-sufficient, not overly engaged with the cash economy (largely subsistence, growing crops for their own consumption), nor reliant on international markets (particularly for spices), the market disturbance had little to no impact.

In South Africa, smallholder farmers cultivating fresh and perishable products (such as fruits, vegetables and dairy) for local markets, struggled to sell produce due to the demand fallout and closure of local informal markets. These farmers had to store perishable farm products on the farm in anticipation of the reopening of informal markets, which led to high post-harvest losses and increased storage costs. Similarly, large-scale commercial apple farmers also incurred losses as demand and prices for apples in the export market crashed after international border restrictions (R2.5 [Rands] per kg in 2020 compared with R13 in 2016). One key informant farmer described how recently harvested apples that had been packed and sent to the market were promptly recalled, unpacked, stored and subsequently repackaged upon the reopening of export markets and demand. In addition to the price crash, such additional packaging and transport costs drastically reduced farmers' profit margins, with implications for the sustainability of future harvests:

"The worst influence is going to be on smaller or medium-scale commercial farmers that are producing food ... [these] are going to fall away. You know the financial impact of the apples that were sold at a lower price, with the margin at which I might also fold in a year or two. So, I think the effect is not so much on food availability, but I think that the impact will depend on how many of the farmers are going to be left in 2- or 3-years' time because of this pandemic 
is going to be a big factor. And then your food supply will also be affected."

(Commercial farmer in South Africa)

\subsection{Employment, Income and Labour}

A key impact of COVID-19 was an interruption to on-farm activities. In both study sites, movement restrictions coincided with harvesting and planting times, meaning essential and time-critical activities, dependent on labour, were interrupted. This affected the quality and quantity of production, slowing down operations and increased the cost of production and, subsequently, market price for farm products.

In Tanzania, restricted movement between areas and a ban on group congregation, coupled with increased concern around travel on public transport and of those who had recently travelled, reduced the availability of seasonal migrant labour. However, although migrant labour reportedly declined, one key informant explained how local labour availability increased as people were actively avoiding urban areas and favoured more isolated employment opportunities on farms:

"People [were] interested to spend their days on the farms, [ ... ] they preferred to work on the farm the whole day than staying on the streets. So, it simplified availability of labourers, even when you tell someone that I just have 2000 [Tz Shillings] they agreed to work on the farm, rather than staying on the street and interacting with the other people." (Farmer in Tanzania)

Alongside a change in labour availability, the ability to pay for labour declined for some key informant farmers in Tanzania, due to reduced overall incomes resulting from COVID-19-associated reductions in crop sales. Key informant farmers explained how reduced labour availability delayed time-critical farm management activities, such as planting and weeding, with expectations of reduced yields.

In South Africa, local lockdowns from March to June 2020 coincided with the harvesting period for maize, apples and potatoes. The lockdowns imposed social distancing measures and reduced the availability of skilled labour to operate machinery, restricted harvesting and processing capacities and slowed down operations. Some key informant farmers expressed concerns over expected reductions in profit margins.

The national lockdown in South Africa and an associated rise in unemployment and loss of income of non-salaried informal workers equated to reduced domestic demand for perishable food products, such as fruits, vegetables, meat, fish, milk and eggs. Overnight closure of restaurants and decreased business for the food catering sector further reduced local demand, especially for fish, potatoes and livestock products. Emergent and large-scale commercial farmers were affected by the closure of retail food businesses and domestic markets. Closure of schools and travel restrictions also caused the suspension of South Africa's National School Nutrition Programme (NSNP). The suspension of the NSNP affected some smallholder and emerging farmers because contracts with Government schools were postponed or unfilled, consequently resulting in loss of regular income.

The South African Social Security Agency (SASSA) provided food parcels, which aimed to provide staple foods to food-insecure citizens. The food parcels created highly localised demand surges for dry beans, maize and soya. One key informant explained how commercial farmers had benefited, as local selling prices of dry beans, maize and soya had increased due to the food parcels, and market access was enhanced as farmers were selling at the farmgate.

\subsection{Input Supply Chain Impacts}

Key informant interviews in both South Africa and Tanzania highlighted how, due to lower-than-expected crop sales, reduced incomes affected the ability of smallholder farmers to purchase farm inputs, such as seeds, chemical fertilisers and essential services, including livestock vaccinations and medicines. The closure of farm shops and travel restrictions was also an issue across both case study areas, limiting access to seeds, chemical 
inputs (e.g., pesticide, synthetic fertiliser) and livestock medical supplies, especially for smallholder farmers.

In South Africa, respondents articulated a range of impacts associated with the differences in production systems. For example, input suppliers and shop representatives were unable to visit farms due to travel restrictions, which delayed or disrupted time-critical farming activities and increased the costs for some. Commercial farmer respondents also explained how it was particularly challenging to obtain harvest loans and agriculture investments:

"COVID also hit people, and what is interesting, and I believe is directly connected to COVID is the financing this year, especially harvesting loans, is a major problem. We have not received any money up until now, for the new year's inputs. So, I think in that aspect, it has big repercussions because I think the banking sector also suffered in this time." (Commercial farmer in South Africa)

In one interview with an Emergent Farmer, issues around border closures in South Africa and subsequently reduced availability of inputs, specifically livestock medicine, were highlighted. Another emerging livestock farmer reported similar shortages in animal feed, explaining how the international import supply chains for dry beans (Phaseolus vulgaris) from countries such as China were severely disrupted due to border restrictions. A shortage of imported feed resulted in increased demand for local sources, such as dry beans and soya. Five key informants further described how challenges with livestock health, particularly of cattle and sheep, were compounded by a shortage of feed and low water availability due to a poor rainfall season in 2020.

Two smallholder key informants in South Africa voiced a sense of injustice at their predicament, feeling that larger-scale farmers benefitted from better access to capital, markets and information and could transport their produce to the border even in the lockdown.

“... because with new regulations put in place, small farmers like me would not be able to sell that much ... only the commercial farmers will benefit. There is something called paying when buying, so for livestock, I don't have money to pay the doctor if the doctor has to visit my farm for vaccinations." (Small-scale farmers in South Africa)

Similarly, one commercial farmer also highlighted the disparity in the support provided by the government concerning the emerging farmers. According to the respondent, the government offered emerging farmers loans at lower interest rates ( $8 \%$ ) compared to what commercial farmers received at commercial banks (12-14\%). The Land Bank loans could not be accessed by the commercial farmers even if they were struggling.

Despite the variety of production systems and associated impacts on input supply, as the two quotes below illustrate, respondents in South Africa felt that ultimately, the low availability and limited access to farm inputs would have repercussions on agricultural activities and outputs, with implications for income generation:

"It is possible, because if we plant, we might need insecticides and if shops are closed, we could not be able to buy and use it on our crops [... ] We may have loss in our productions due to chemical shortages." (Emerging land reform farmer in South Africa)

\subsection{Impacts of COVID-19 on Farmer-Livelihoods}

For smallholder farmers in Tanzania, livelihoods were diverse and dependent on a range of off-farm income-generation activities. Several off-farm activities were affected by COVID-19, mainly commercial food businesses reliant on large groups of customers, such as selling tea and buns for school children, and the sale of poultry for consumption at social events. For one key informant in Tanzania, who owned and ran a village shop, sourcing stock was challenging due to localised travel restrictions.

Compounded losses from off-farm income and agricultural sales caused reductions in buying power for smallholder farmers; school closures also impacted some household budgets. As a result, several key informants in Tanzania reported reduced consumption of 
more expensive food items, including meat, sugar, rice and milk. Similar experiences were reported during interviews with small-scale farmers in South Africa:

"Sometimes we get food from the shops, sometimes not. Especially cabbage is very scarce. Transport is not the problem, but I had to stop travelling because of the coronavirus situation." (Small-scale farmer in South Africa)

"I don't cultivate food crops to the great extent, I depend food from the shops. When I sell cash crops I can buy like one bag of flour and one bag of rice, I store them in the house. But now I don't have money to buy them." (Emerging farmer in South Africa)

In South Africa, smallholder farmer households typically sought additional employment, often as seasonal labour on larger farms. However, travel restrictions and social distancing measures resulted in unemployment and loss of disposable income for many. Challenges with financial viability were raised by farmers working at all scales in South Africa. For example, one commercial farmer felt that the longer-term financial security of smallholder and smaller-scale commercial producers were at risk, with the loss of producers linked to a potential rise in food insecurity. However, not all farmers were as pessimistic. Two commercial farmer respondents felt that COVID-19 itself would not impact food production because disease risk could be mitigated through preventive social distancing and sanitisation measures.

Most emerging and commercial farmer respondents in South Africa mentioned farm thefts as a significant challenge, with several reporting thefts of livestock, stored grain and agricultural equipment. A commercial farmer observed how the frequency of farm thefts had reduced during the first three weeks of lockdown (starting 21 May 2020), then subsequently increased once the movement was permitted in the region. Loss of income and increased poverty during COVID-19 was a speculative reason for the increase in theft.

"Security is our single worst downturn that we've had, theft and support from police has been dismal. Absolutely dismal [ ... ] We have literally lost hundreds of thousands [of rands] in that regard. So that's been, I'd say, the worst. Whether it's a result of the COVID-19, I don't know. One could argue that the COVID has resulted in more poverty and more reliance on theft and that sort of thing ... " (Commercial farmer in South Africa)

\subsection{Compounded Shocks}

In South Africa specifically, respondents explained how successive climatic challenges, followed by COVID-19, created compounded issues. Many respondents mentioned planting unusually late in the season, at the end of November 2019, following the rains that arrived mid-month. Respondents explained how the delayed planting was followed by early onset of frost, severely reducing the growing season. This required farmers to use chemical fertilisers and pesticides, livestock and short-season crop varieties, subsequently squeezing profit margins. Other respondents also mentioned drought and lack of water for irrigating crops and pasture as major weather-related problems, alongside impacts from crop pests and diseases, which became worse due to lack of access to inputs. Many smallholders and emerging farmers in South Africa voiced concern for future farm productivity and resultant food shortages over the following 1-2 years due to longer-term compounded impacts of COVID-19 and annual drought. As the quote below illustrates, the disruption caused by COVID-19 pushed some farmers out of business:

"Two farmers I know in our area that are bigger, and I saw them as wealthier farmers than what I was, have folded, have gone bankrupt in the last two months. They have been sold out. It is not only now because of COVID but also, it has been coming for a time and harshness of COVID-19 was just absolutely the nail in the coffin." (Commercial farmer in South Africa) 


\subsection{Coping Mechanisms}

Respondents reported a range of coping mechanisms in response to the acute impacts of COVID-19 measures. Smaller farm systems coped with labour and market impacts differently than their larger-scale counterparts. In Tanzania, for example, many smallholders operated in more subsistence and localised systems. Here, potential COVID-19 impacts were minimised by trading services and food products among themselves. Similarly, amongst smallholders in South Africa, respondents reported drawing on family labour to reduce the costs and uncertainties associated with the labour shortage.

Smallholder respondents in South Africa also explained how they had increased consumption of their own produce and delivered produce directly to buyers or at the farmgate. Emerging farmer respondents similarly reported sharing labour and renting out land, as well as selling assets (such as livestock) as short-term relief. Smallholders and emerging farmers also reported reducing the quantity of crops (mainly vegetables) planted in March-April, due to the growing uncertainty associated with COVID-19 restrictions and limited available capital.

Commercial farmers in South Africa, more dependent on global supply chains, single commodities with longer supply chains, mechanisation and hired labour, were perhaps more affected than smallholder farmers by the closure of national and international markets and social distancing measures. However, with access to more capital, commercial farmers had more financial resources to draw on. Several commercial farmers explained how they had pre-emptively bought inputs before lockdown started and built storage infrastructure. Some commercial farmers were also able to use their own transport to procure agricultural inputs and transport labourers. Commercial farmers reported devising innovative solutions to mitigate social distancing measures, such as alternative work schedules and adopting shift-work. In comparison, some of the emergent farmers were the worst hit: with enterprises too big to run on family labour, but without the capital access needed to ride out the crisis.

Technology became an important communication tool across both study sites, with commercial farmers in South Africa relying more on digital services (e.g., conducting farmers meetings using online platforms) for communication and knowledge sharing. Smallholder respondents in Tanzania similarly explained how mobile phones became a vital tool to order household essentials from the nearby town and reduce their need to travel.

In reflecting on pre-emptive solutions and potential adaptive measures, respondents across both countries underlined the importance of developing storage infrastructure and mechanisms, such as drying produce, both in anticipation of market resurgence and to protect food security:

"Due to COVID-19, people are now aware and very careful that they should store food after harvesting. I teach people about farming practices [and] people have been asking about storage bags for cereals. People have been asking about them, so I' $m$ in the process of finding them. This is because of COVID-19, as people are aware that they should get prepared for hard moments like this." (Farmer in Tanzania)

In an interview with a village chairman in Tanzania, the respondent underlined the importance of diversifying production systems to balance both food and cash crops to support local food security. The respondent also highlighted the role of local institutions in providing community preparedness support:

"Coronavirus opened our minds. When the disease [COVID-19] arises, and you don't have those crops, it will affect your household, resulting in hunger for your family. We are now cultivating drought resistant [food] crops like cassava, potatoes, banana, and some people have planted short term crops. As leaders, we have our strategy to go to each household to look at the activities people are doing. If we find someone not prepared well, we put our efforts to help him by 
advising him to make sure he is not affected by the shortage of food." (Village Chairperson in Tanzania)

\section{Discussion}

The COVID-19 pandemic caused an Anthropause-global human confinement, providing an opportunity to evaluate the impacts of anthropogenic activities and assess the sustainability of systems that underpin human survival and well-being [46]. The pandemic also underlined the vulnerabilities of the world's food systems and food supply chains and has fuelled intense discussions about what constitutes a resilient food system [47].

These discussions involved debates on vulnerabilities and resilience of different production models and supply chains, e.g., large-scale vs. small-scale and local or domestic vs. global [48]. Here, large-scale means big enterprise farms ranging from 200-1000 hectares in size and mainly engaged in global chains by producing foods or agricultural raw materials consumed in another country. Small-scale farms are less than 10 ha, functioning as small and medium enterprises (SMEs) and mainly producing food for domestic consumption, i.e., local, regional or national markets. In the context of this study, the emerging farms in South Africa are often classed as small-scale or SMEs as they mainly serve domestic markets even though they may be bigger in terms of farm sizes. The SMEs, categorised by domestic value chains, account for over $75 \%$ of the food consumed in Africa. In contrast, large-scale enterprises engaging in global chains contribute to $\sim 20 \%$ of food consumption in the region.

This study found that more self-reliant farmers-Tanzanian smallholders-who grew food crops alongside cash crops coped better. This finding matches with observations in other similar studies across different geographies [49-51].

Furthermore, institutional and community support played an important role in reducing dependencies on external actors affected by the pandemic (e.g., buyers of cash crops or suppliers of food crops). Farmers in Tanzania often shared food products, labour and taught each other best practices (e.g., storage) to enable better coping. In contrast, South African farmers were more dependent on markets and were significantly affected by logistical bottlenecks in the value chain and the reduced market demands and buying power. SMEs in South Africa were more reliant on domestic markets and were severely affected when the buying power of the population was reduced due to income losses [23].

Our study explores how the different production models coped under COVID-19. Based on the insights obtained from the two countries and diverse range of production models, we propose policy actions, described below, to improve coping of food production systems to future value chain shocks.

\subsection{Social and Financial Support for the Informal Sector}

Our study demonstrated how COVID-19 movement restrictions and social-distancing measures triggered acute labour shortages, complementing the work of others [18]. Labour shortages affected on-farm activities, increased processing times after harvest and caused post-harvest losses as the produce was kept on-farm for longer durations and increased operation and storage costs [52]. Addressing labour constraints in the food supply chain is crucial for building food system resilience. By designating agriculture sector workers. both public and private, as critical, providing travel arrangements for essential workers and allowing for easy and on-farm delivery of work permits and identity cards required by the government, could allow movement for agriculture workers in times of travel restrictions and lockdowns.

Further, in most cases, workers' fear of contracting COVID-19 impeded their availability to work on the farms. Some of the farm owners in our study sites in South Africa overcame this problem by taking measures to ensure the health and safety of workers. These farm owners provided transport and ensured lower worker density and sanitation in the farm and packing and processing facilities. Thus, awareness among farm 
owners and workers and ensuring safe working conditions could be the key to ensuring labour availability.

The pandemic contributed to unemployment and impoverishment due to unprecedented income losses. South Africa and Tanzania both responded to the crisis by announcing COVID-19 specific social assistance and protection in the form of regular cash or food transfers to unemployed adults (only in South Africa) and non-working vulnerable groups (the elderly, children and disabled people, both countries) [53,54]. COVID-19, however, impacted other groups of people, such as informal farmworkers and the self-employed who did not have access to any formal social protection. Furthermore, many vulnerable groups living in remote locations (e.g., small-scale farmers in South Africa) did not receive the social support announced by the governments. Implementation of social protection programs should therefore focus on ensuring that it reaches the eligible and vulnerable groups and expands to the groups most vulnerable to COVID-19 specific impacts. Sustainability impact assessments [55] may provide a structured approach to support the design and evaluation of post-pandemic initiatives, taking into account economic, social and environmental impacts.

\subsection{Employment and Job Security in Agriculture}

Interviews highlighted how some farmers struggled to hire labour because of lower farm income resulting from reduced agricultural activity, production and markets. Food, or food and cash for work schemes, may provide safety net opportunities for both farmers and labourers [56]. Such a system can be further adapted to allow triple benefits [21] by employing the labourers beyond planting and harvesting and engaging them in constructing infrastructure, such as food storage and water storage facilities to improve agriculture resilience under COVID-19, climate or similar shocks. In South Africa, farmers can only hire temporary, seasonal labourers at the minimum daily wage prescribed by the government (mean 146.28 Rands per day in 2020). However, this may be unaffordable for many farmers $[57,58]$. Where employing labourers beyond planting and harvesting is not feasible, policies must focus on capacity building of such temporary, seasonal labourers allowing them to develop skills and knowledge with a particular emphasis on managerial training, agro-processing and value addition of agro-products, which will allow them to become more employable in the food supply system. Furthermore, creating opportunities to facilitate an alternative workforce by drawing upon and training workers laid off in other sectors may also help manage labour constraints.

\subsection{Infrastructural Investment and Support}

Our findings highlighted how farmers relied on digital tools to access markets. With the availability of the internet and cheaper mobile devices, digital applications for communication in SSA are increasing rapidly. Digital solutions will play an increasingly important role in transforming agricultural ecosystems and value chains, and strengthening food supply systems [59], particularly in a post-COVID world.

A digitised marketing system, for example, where buyers, sellers and consumers can communicate directly, could reduce reliance on conventional markets and provide greater adaptability in buyer-producer access. Community marketing refers to partnerships formed among farmers and other local-scale actors (e.g., local extension officers) with the aim of reaching specific segments of buyers [60]. Governments play an important role in recognising and providing financial and technical assistance to such community-led innovative marketing schemes. There is, therefore, a need to focus on building institutional capacity by, for example, providing training to extension officers and farmers in guiding the community marketing schemes and collaborating with farmer groups to use information and communication technologies to support the mobilisation and identification of markets, and transportation of agri-products [61]. 


\subsection{Diversifying Farm Systems}

In our study, farms in Tanzania were comparatively more diversified than farms in South Africa, with multiple crops and tree species being an integral part of the farm system alongside livestock such as dairy cattle and chickens. Diverse farming systems reduce dependency on a single farm commodity, e.g., spice trees, and provides additional benefits in terms of biodiversity-supported ecosystem services-pollination of crops to increase yields and biological control of crop pests and diseases (Altieri and Nicholls 2020b). Diversified mixed cropping systems offer yield stability with low external inputs, improve resilience as diverse agri-systems are able to cope better under environmental and ecological shocks, and reduce the cost of agriculture via provisioning of ecosystem services (MacFall et al., 2015). Promoting diversified agroecosystems is key for building resilience in food production systems, especially in small-scale systems, which occupy over $30 \%$ of global arable land and produce up to $70 \%$ of the food consumed [62].

COVID-19 intersected with other types of production disruptions in our study sites; South African farmers dealt with drought [63], whereas Tanzanian farmers faced flashfloods [64] just before the growing season in November-December. These climate shocks impacted food production by destroying fields, causing delays in planting or shortening the crop season. The climate shocks also increased the cost of production, as farmers needed to spend more on inputs-such as irrigation during drought or fertilisers in the case of reduced soil fertility after flash floods. Building resilience in farm systems should, therefore, incorporate and strengthen farmers' ability to cope with climate shocks alongside other stressors [65].

\section{Conclusions}

This study presents an empirical analysis of COVID-19 impacts on the local farming systems and adaptation strategies employed by farmers in Tanzania and South Africa. Our findings provide evidence of substantial effects on agriculture and food security as a result of COVID-19, through indirect channels of influence leading to (i) income losses and reduced demand, (ii) supply chain disruptions, (iii) altered consumer responses and dietary shifts, (iv) interruptions in international and national trade.

Farmers' coping actions and strategies varied based on the enterprise size, production model, level of capital access and market engagement, and farm-system diversification. Diversified and mixed farming systems, such as those observed in Tanzania, where farmers grew cash and food crops and were less dependent on international markets, were less impacted by COVID-19. Small-scale farmers in South Africa who grew cash crops for local markets and depended on buying food products from local shops, faced a loss of income and increased food insecurity as the variety of food crops they grew was limited. Large-scale commercial farmers dependent on cash and single commodity systems of apple and potatoes suffered economic losses due to market uncertainty and closure. Large-scale farmers with access to capital were able to buy agricultural inputs in advance, and those who had assets, such as livestock, managed to cope by selling those assets. However, the selling of assets in response to COVID-19 impacts may reduce the capacity to cope with future shocks, such as droughts in South Africa and flash floods in Tanzania.

In light of the impacts and coping mechanisms documented in this study, we propose that policy actions should focus on the following: (i) providing temporary relief and social support and protection to financially vulnerable stakeholders, (ii) job assurance for farmworkers and engaging an alternative workforce in farming, (iii) investing in farming infrastructure, such as storage facilities, digital communication tools and extension services, and (iv) supporting diversified farming systems.

Author Contributions: H.G.T. and H.E.S. were co-lead researchers and authors of this study with equal contribution. They conceived the idea and designed this study with the help of S.M.S. (Steven M. Sait), S.M.S. (Susannah M. Sallu) and S.W. All other co-authors (A.J., W.E.K., N.M. and B.N.) provided equal input to the drafting of the manuscript, hence are listed in alphabetical order. All authors have read and agreed to the published version of the manuscript. 
Funding: This work was funded by the Biotechnology and Biological Sciences Research Council through UK Research and Innovation, as part of the Global Challenges Research Fund: AFRICAP Programme, grant number BB/P027784/1. Research in Tanzania was conducted under COSTECH permit number: 2019-305-NA-2016-101.

Institutional Review Board Statement: The study was conducted according to the guidelines of the University of Leeds Research Ethics Policy and approved by the Ethics Committee of the School of Earth and Environment, University of Leeds (AREA 19-173 and August 2020).

Informed Consent Statement: Informed consent was obtained from all subjects involved in the study.

Data Availability Statement: The data presented in this study are available on request from the corresponding author.

Acknowledgments: Research in South Africa was facilitated through support from our local partners (National Agricultural Marketing Council and Agricultural Research Council). Research in Tanzania was supported by the Economic and Social Research Foundation. We are very grateful to the community members who gave their valuable time to participate in interviews. Special thanks go to Hendri Stander, Teboho Mofokeng, Lisemelo Motholo in South Africa, Elimeena Baraka, Mosha Florence and Manzil Maburuki in Tanzania for their support with data collection.

Conflicts of Interest: The authors declare no conflict of interest. The funders had no role in the design of the study, in the collection, analyses or interpretation of data, in the writing of the manuscript or in the decision to publish the results.

\section{References}

1. Laborde, D.; Vos, R. Impacts of COVID-19 on global poverty, food security, and diets: Insights from global model scenario analysis. Agric. Econ. 2021, 52, 375-390. [CrossRef] [PubMed]

2. Laborde, D.; Martin, W.; Swinnen, J.; Vos, R. COVID-19 risks to global food security. Science 2020, 369, 500-502. [CrossRef]

3. Arndt, C.; Davies, R.; Gabriel, S.; Harris, L.; Makrelov, K.; Robinson, S.; Levy, S.; Simbanegavi, W.; van Seventer, D.; Anderson, L. Covid-19 lockdowns, income distribution, and food security: An analysis for South Africa. Glob. Food Sec. 2020. [CrossRef]

4. Udmale, P.; Pal, I.; Szabo, S.; Pramanik, M.; Large, A. Global food security in the context of COVID-19: A scenario-based exploratory analysis. Prog. Disaster Sci. 2020, 7, 100120. [CrossRef]

5. Moseley, W.G.; Battersby, J. The Vulnerability and Resilience of African Food Systems, Food Security, and Nutrition in the Context of the COVID-19 Pandemic. Afr. Stud. Rev. 2020, 63, 449-461. [CrossRef]

6. OECD. Building a coherent response for a sustainable post-COVID-19 recovery. OECD Publ. 2020. [CrossRef]

7. Mbow, B.M.; Lell, B.; Jochems, P.; Cisse, B.; Dewals, B.G.; Jaye, A.; Dieye, A.; Yazdanbakhsh, M. COVID-19 in Africa: Dampening the storm? Science 2020, 369, 624-627. [CrossRef]

8. Dang, H.-A.H.; Dabalen, A.L. Is Poverty in Africa Mostly Chronic Or Transient? Evidence from Synthetic Panel Data. J. Dev. Stud. 2017, 55, 1527-1547. [CrossRef]

9. Niang, I.; Ruppel, O.C.; Abdrabo, M.A.; Essel, A.; Lennard, C.; Padgham, J.; Urquhart, P. Climate Change 2014—Impacts, Adaptation and Vulnerability: Part B: Regional Aspects; Cambridge University Press: Cambridge, UK, 2014; pp. 1199-1266. [CrossRef]

10. Smith, J. Crops, Crop Pests and Climate Change-Why Africa Needs to Be Better Prepared; CGIAR Research Program on Climate Change, Agriculture and Food Security: Copenhagen, Denmark, 2015.

11. Tambo, J.A.; Day, R.K.; Lamontagne-Godwin, J.; Silvestri, S.; Beseh, P.K.; Oppong-Mensah, B.; Phiri, N.A.; Matimelo, M. Tackling fall armyworm (Spodoptera frugiperda) outbreak in Africa: An analysis of farmers' control actions. Int. J. Pest Manag. 2020. [CrossRef]

12. Salih, A.A.M.; Baraibar, M.; Mwangi, K.K.; Artan, G. Climate change and locust outbreak in East Africa. Nat. Clim. Chang. 2020, 10, 2019-2020. [CrossRef]

13. Berazneva, J.; Lee, D.R. Explaining the African food riots of 2007-2008: An empirical analysis. Food Policy 2013, 39, 28-39. [CrossRef]

14. Amimo, F.; Lambert, B.; Magit, A. What does the COVID-19 pandemic mean for HIV, tuberculosis, and malaria control? Trop Med. Health 2020. [CrossRef] [PubMed]

15. Speranza, C.I.; Wiesmann, U.; Rist, S. An indicator framework for assessing livelihood resilience in the context of social-ecological dynamics. Glob. Environ. Chang. 2014. [CrossRef]

16. Makate, C.; Makate, M.; Mango, N.; Siziba, S. Increasing resilience of smallholder farmers to climate change through multiple adoption of proven climate-smart agriculture innovations. Lessons from Southern Africa. J. Environ. Manage. 2019, 231, 858-868. [CrossRef]

17. Javadinejad, S.; Dara, R.; Jafary, F. Analysis and Prioritization the Effective Factors on Increasing Farmers Resilience Under Climate Change and Drought. Agric. Res. 2020, 10, 497-513. [CrossRef] 
18. Ayanlade, A.; Radeny, M. COVID-19 and food security in Sub-Saharan Africa: Implications of lockdown during agricultural planting seasons. npj Sci. Food 2020, 4, 13. [CrossRef] [PubMed]

19. de Graaff, J.; Kessler, A.; Nibbering, J.W. Agriculture and food security in selected countries in Sub-Saharan Africa: Diversity in trends and opportunities. Food Secur. 2011, 3, 195-213. [CrossRef]

20. Béné, C. Resilience of local food systems and links to food security-A review of some important concepts in the context of COVID-19 and other shocks. Food Secur. 2020, 12, 805-822. [CrossRef]

21. Amjath-Babu, T.S.; Krupnik, T.J.; Thilsted, S.H.; McDonald, A.J. Key indicators for monitoring food system disruptions caused by the COVID-19 pandemic: Insights from Bangladesh towards effective response. Food Secur. 2020, 12, 761-768. [CrossRef]

22. Gordon, L.J. The Covid-19 pandemic stress the need to build resilient production ecosystems. Agric. Hum. Values 2020. [CrossRef]

23. Duguma, L.A.; van Noordwijk, M.; Minang, P.A.; Muthee, K. COVID-19 pandemic and agroecosystem resilience: Early insights for building better futures. Sustainability 2021, 13, 1278. [CrossRef]

24. Shilomboleni, H. COVID-19 and food security in Africa: Building more resilient food systems. AAS Open Res. 2020. [CrossRef] [PubMed]

25. Altieri, M.A.; Nicholls, C.I. Agroecology and the reconstruction of a post-COVID-19 agriculture. J. Peasant Stud. 2020, 47, 881-898. [CrossRef]

26. DEA. South Africa Yearbook 2018-19-Agriculture, Forestry and Fisheries; United States Drug Enforcement Administration: Springfield, VI, USA, 2019.

27. Sikwela, M.; Fuyane, N.; Mushunje, A. The role of cooperatives in empowering smallholder farmers to access markets: A case study of Eastern Cape and KwaZulu Natal cooperatives in South Africa. Int. J. Dev. Sustain. 2016, 5, 536-552.

28. White Paper on South African Land Policy April 1997. Available online: https://www.gov.za/sites/default/files/gcis_document/ 201411/whitepaperlandreform.pdf (accessed on 21 April 2021).

29. Cliffe, L. Land reform in South Africa. Rev. Afr. Polit. Econ. 2000, 27, 273-286. [CrossRef]

30. Tibesigwa, B.; Visser, M.; Turpie, J. Climate change and South Africa's commercial farms: An assessment of impacts on specialised horticulture, crop, livestock and mixed farming systems. Environ. Dev. Sustain. 2017, 19, 607-636. [CrossRef]

31. Sallu, S.; Gaworek-Michalczenia, M.; Pilato, G. Baseline Report for GCCA+Integrated Approaches for Climate Change Adaptation Programme in the East Usambara Mountains; University of Leeds: Leeds, UK, 2018.

32. Conte, C. A Highland Sanctuary: Environmental History in Tanzania's Usambara Mountains. Ohio Univ. Press 2004, 10, 548-550. [CrossRef]

33. Chapman, S.; E Birch, C.; Pope, E.; Sallu, S.; Bradshaw, C.; Davie, J.; H Marsham, J. Impact of climate change on crop suitability in sub-Saharan Africa in parameterized and convection-permitting regional climate models. Environ. Res. Lett. 2020, 15, 094086. [CrossRef]

34. Winowiecki, L.; Vågen, T.G.; Massawe, B.; Jelinski, N.A.; Lyamchai, C.; Sayula, G.; Msoka, E. Landscape-scale variability of soil health indicators: Effects of cultivation on soil organic carbon in the Usambara Mountains of Tanzania. Nutr. Cycl. Agroecosystems 2016, 105, 263-274. [CrossRef]

35. Wynants, M.; Kelly, C.; Mtei, K.; Munishi, L.; Patrick, A.; Rabinovich, A.; Nasseri, M.; Gilvear, D.; Roberts, N.; Boeckx, P.; et al. Drivers of increased soil erosion in East Africa's agro-pastoral systems: Changing interactions between the social, economic and natural domains. Reg. Environ. Chang. 2019, 19, 1909-1921. [CrossRef]

36. Bello, A.H.; Scholes, M.; Newete, S.W. Impacts of agroclimatic variability on maize production in the setsoto municipality in the free state province, south africa. Climate 2020, 8, 147. [CrossRef]

37. Myeni, L.; Moeletsi, M.; Thavhana, M.; Randela, M.; Mokoena, L. Barriers affecting sustainable agricultural productivity of smallholder farmers in the eastern free state of South Africa. Sustainability 2019, 11, 3003. [CrossRef]

38. ECA. COVID-19: Lockdown Exit Strategies for Africa. Econ. Comm. Afr. 2020. [CrossRef]

39. Saleh, M. Impact of COVID-19 on Tanzania Political Economy. Int. J. Adv. Stud. Soc. Sci. Innov. 2020, 1. [CrossRef]

40. DPSA State of Disaster: Guidelines for the Management of the CORONA Virus (COVID-19) in the Public Service by the Republic of South Africa. Available online: https://www.gov.za/sites/default/files/pictures/publicservice-guidelines-disaster.pdf (accessed on 21 April 2021).

41. Gazette, S.G. South Africa Disaster Management Act, 2002: Amendment of Regulations Issued in Terms of Section 27(2). Available online: https:/ / www.gov.za/sites/default/files/gcis_document/202004/43232rg11089gon465-translations_0.pdf (accessed on 21 April 2021).

42. Fereday, J.; Muir-Cochrane, E. Demonstrating Rigor Using Th ematic Analysis: A Hybrid Approach of Inductive and Deductive Coding and Theme Development. Int. J. Qual. Methods 2006, 5, 80-92. [CrossRef]

43. Chapman, A.L.; Hadfield, M.; Chapman, C.J. Qualitative research in healthcare: An introduction to grounded theory using thematic analysis. J. R. Coll. Physicians Edinb. 2015, 45, 201-205. [CrossRef] [PubMed]

44. Vaismoradi, M.; Turunen, H.; Bondas, T. Content analysis and thematic analysis: Implications for conducting a qualitative descriptive study. Nurs. Heal. Sci. 2013, 15, 398-405. [CrossRef] [PubMed]

45. AlYahmady, H.H.; Al Abri, S.S. Using Nvivo for Data Analysis in Qualitative Research. Int. Interdiscip. J. Educ. 2013, 2, 181-186. [CrossRef] 
46. Rutz, C.; Loretto, M.C.; Bates, A.E.; Davidson, S.C.; Duarte, C.M.; Jetz, W.; Johnson, M.; Kato, A.; Kays, R.; Mueller, T.; et al. COVID-19 lockdown allows researchers to quantify the effects of human activity on wildlife. Nat. Ecol. Evol. 2020, 4, 1156-1159. [CrossRef]

47. Nasereldin, Y.A.; Brenya, R.; Bassey, A.P.; Ibrahim, I.E.; Alnadari, F.; Nasiru, M.M.; Ji, Y. Is the Global Food Supply Chain during the COVID-19 Pandemic Resilient? A Review Paper. Open J. Bus. Manag. 2021, 9, 184-195. [CrossRef]

48. MacFall, J.; Lelekacs, J.M.; LeVasseur, T.; Moore, S.; Walker, J. Toward resilient food systems through increased agricultural diversity and local sourcing in the Carolinas. J. Environ. Stud. Sci. 2015, 5, 608-622. [CrossRef]

49. Ceballos, F.; Kannan, S.; Kramer, B. Impacts of a national lockdown on smallholder farmers' income and food security: Empirical evidence from two states in India. World Dev. 2020, 136, 105069. [CrossRef]

50. Middendorf, B.J.; Faye, A.; Middendorf, G.; Stewart, Z.P.; Jha, P.K.; Prasad, P.V.V. Smallholder farmer perceptions about the impact of COVID-19 on agriculture and livelihoods in Senegal. Agric. Syst. 2021, 190, 103108. [CrossRef] [PubMed]

51. Goswami, R.; Roy, K.; Dutta, S.; Ray, K.; Sarkar, S.; Brahmachari, K.; Nanda, M.K.; Mainuddin, M.; Banerjee, H.; Timsina, J.; et al. Multi-faceted impact and outcome of COVID-19 on smallholder agricultural systems: Integrating qualitative research and fuzzy cognitive mapping to explore resilient strategies. Agric. Syst. 2021, 189, 103051. [CrossRef]

52. Ceylan, R.F.; Ozkan, B.; Mulazimogullari, E. Historical evidence for economic effects of COVID-19. Eur. J. Health Econ. 2020, 21, 817-823. [CrossRef] [PubMed]

53. Devereux, S. Social protection responses to COVID-19 in Africa. Glob. Soc. Policy 2021. [CrossRef]

54. South Africa Economic Update: South Africa's Labor Market Can Benefit from Young Entrepreneurs, Self-Employment. Available online: https:/ / www.worldbank.org/en/country/southafrica/publication/south-africa-economic-update-south-africa-s-labormarket-can-benefit-from-young-entrepreneurs-self-employment (accessed on 21 April 2021).

55. Kumar, L.R.; Talan, A.; Tyagi, R.D. Sustainable Impact Assessment. In Sustainability; European Commission: Brussels, Belgium, 2020.

56. Abebe, G. Cash-for-work and food-for-work programmes role in household resilience to food insecurity in southern Ethiopia. Dev. Pract. 2020, 30, 1068-1081. [CrossRef]

57. Kriel, G. “Farmers Cannot Afford To Pay Higher Wages”-Agri Role Players. Available online: https://www.farmersweekly.co za/agri-news/south-africa/farmers-cannot-afford-to-pay-higher-wages-agri-role-players/ (accessed on 21 April 2021).

58. The Potential Impact of the National Minimum Wage on the Agricultural Sector-An Analysis of Agricultural Wages in South Africa; Bureau for Food and Agricultural Policy: Pretoria, South Africa. 2019. Available online: http:/ /www.bfap.co.za/wpcontent/uploads /reports / 2018\%2006_Implications \%20of $\% 20$ the $\% 20$ national $\% 20$ minimum $\% 20$ wage $\% 20$ in $\% 202018 \% 20 \& \% 2$ 02019_Final\%20draft.pdf (accessed on 21 April 2021).

59. Baumüller, H.; Kah, M.M.O. Going digital: Harnessing the power of emerging technologies for the transformation of Southern African agriculture. In Transforming Agriculture in Southern Africa: Constraints, Technologies, Policies and Processes; Routledge: Oxfordshire, UK, 2019; ISBN 9780429401701.

60. Thakur, R. Community marketing: Serving the base of the economic pyramid sustainably. J. Bus. Strategy 2015, 36, 40-47. [CrossRef]

61. Chander, M.; Rathod, P. Reorienting Priorities of Extension and Advisory Services in India during and Post COVID-19 Pandemic: A Review. Indian J. Ext. Educ. 2020, 56,1-9.

62. Altieri, M.A.; Nicholls, C.I. Agroecology and the emergence of a post COVID-19 agriculture. Agric. Hum. Values 2020, 37, 525-526. [CrossRef]

63. Elum, Z.A.; Modise, D.M.; Marr, A. Farmer's perception of climate change and responsive strategies in three selected provinces of South Africa. Clim. Risk Manag. 2017, 16, 246-257. [CrossRef]

64. Smith, H.; Tripathi, H.; Galani, J.; Exe, S.; Chapman, S. Extreme Rainfall and Flooding in the East Usambaras—Challenges and Solutions: GCRF-AFRICAP; University of Leeds: Leeds, UK, 2020. Available online: https://gtr.ukri.org/projects?ref=BB\%2FP027784\%2F1 (accessed on 21 April 2021).

65. Lipper, L.; McCarthy, N.; Zilberman, D.; Asfaw, S.; Branca, G. Climate Smart Agriculture Building Resilience to Climate Change; Springer International Publishing: New York, NY, USA, 2018; ISBN 978-3-319-61194-5. 